The PhD System Under Pressure: An Examiner's Viewpoint

\begin{tabular}{|r|l|}
\hline Journal: & Quality Assurance in Education \\
\hline Manuscript ID & QAE-04-2018-0033.R1 \\
\hline Manuscript Type: & Assessment Policy Article \\
\hline Keywords: & Doctorate, PhD degree, Examination, Pedagogy, Review of practice \\
\hline \multicolumn{2}{|}{} \\
\hline
\end{tabular}

SCHOLARONE $^{\text {In }}$

Manuscripts 


\section{The PhD System Under Pressure: An Examiner's Viewpoint}

\section{Introduction}

The PhD degree has been described by educationalists as "the pinnacle of academic

5 qualifications in higher education" (Denicolo 2003, p. 84). In recent decades, it has become accessible to more and more students, to the point that some authors (e.g. Cyranoski et al. 2011) have written about overproduction. In our opinion, that is the least of its problems. In a world dominated by accelerating social, economic and technological change, universities are under immense pressure to adapt, and the $\mathrm{PhD}$ degree, as an institution, is by no means isolated from such forces. But are they beneficial or detrimental? With the intention of systematically considering the issues that currently bear upon the degree, this article reviews some academic studies of the $\mathrm{PhD}$ as a phenomenon that consists of a process and an outcome. In order to produce a critique of examination processes and a warning about what current trends may mean for the future, we draw on our experience of examining $\mathrm{PhD}$ theses. We received our PhDs in 1977 and 1985, respectively, and we have been practising academics ever since then. We have thus accumulated a wealth of experience of supervising PhD research and examining theses. This paper builds upon our previous critique (Alexander and Davis 2014) and suggests a classification of 20 problems that assail the modern PhD degree. We believe that, not only is the academic doctorate the pinnacle of qualifications, it is-or should be-a gold standard for quality and rigour. The $\mathrm{PhD}$ graduates of today will teach and mentor those of tomorrow. This is the highest level of knowledge transfer and we cannot afford to let standards slip. 
This article begins with a review of academic literature on the $\mathrm{PhD}$ with respect to how the degree is formulated, applied and examined. We then move on to a critique of the examination process, or in other words of the outcome of doctoral studies. As Grabbe (2003, p. 128) noted, "Research examining seems to attract anecdotes like a magnet." He added that the anecdotes are most commonly of the tragic kind. Although between us we have accumulated a rich fund of anecdotes, indeed, of horror stories, about examining PhDs, we are more concerned to analyse them in the form of a systematic overview of what can go wrong and what might need to be put right. Finally, we return to the literature and consider some answers to the issues raised by our analysis. We believe that the $\mathrm{PhD}$ is under threat from powerful forces in academia that risk causing quality to be compromised and we hope that by examining these issues we can make a modest contribution that will help maintain standards.

\section{Studies of studies: academic investigations of the PhD in the modern world}

40 In this article, we are not concerned with the literature on how to study for a PhD or how to prepare for the viva examination. We are occupied instead with the academic literature that analyses the $\mathrm{PhD}$ degree as a phenomenon, a piece of pedagogy, an instrument of learning or an indicator of the human condition. Most of this comes from the United Kingdom and Australasia. In the 1990s in Australia there were conferences on the subject and these set off a train of interest that has produced some continuity of interest among academics, albeit in a fairly thin and sporadic form. The relevant research output in the United Kingdom is similarly inconsistent and in the United States it is almost non-existent. This is probably because the main 
emphasis has been on creating and running PhD courses. Any analysis has been for

50 the purposes of internal audits and reports, not to contribute to the general literature on higher education. Rather than in fully academic journals, much of the commentary has appeared in what we might call 'trade' journals, such as Times Higher Education in the UK and the Chronicle of Higher Education in the USA. We are mainly concerned here with peer-reviewed publications, as these have greater weight and 55 longevity.

To begin with, a small number of books have been published on the PhD. These are of three kinds: a manual on "how to do it" (Tinkler and Jackson 2004); a pedagogical survey (Nerad and Heggelund 2008); and methodological debates (Aitchison et al. 2010, Lee and Danby 2011). Taken together, they offer a reasonable overview of the topic from various perspectives, although not of a kind that solicits controversy. A very few works have dealt with the history of the PhD. Park (2005) noted that it is a relatively modern phenomenon, having developed in Germany in the 1860s and Britain after the First World War. Taylor (2011, p. 261) took the opposite view when he argued that "Most doctoral-education programmes conform to a model defined in European universities during the Middle Ages." A compromise explanation might suggest that the present-day $\mathrm{PhD}$ is a relatively modern institution, but one with ancient roots.

Whatever its roots, the $\mathrm{PhD}$ degree is by no means a homogeneous phenomenon. In fact, it differs in organisation, specification, duration, composition, 70 prestige and quality control from one country to another, and indeed from one institution, or even one university department, to another. The one common thread is that the output of PhD graduates is growing steadily and strongly around the world 
(Andersen and Hammarfelt 2011). Not only are more doctoral students at work in departments than were there in previous decades, more institutions are venturing into doctoral studies. Both Nerad and Heggelund (2008) and Cyranoski et al. (2011) have compared some international models. There is a drive to define both lower and higher standards. Cyranoski et al. (2011) argued that in China, for example, training is too short, supervisors are poorly qualified, standards are low and criteria for assessment are absent. In Italy, the doctorate was first proposed in 1980 and was 80 introduced in the 1990s. Foreign doctorates are not automatically recognised as legitimate qualifications, and the legal status of the Italian doctorate is precarious. Because it is a recent innovation, many of the supervisors of doctorates in Italy do not have the qualification themselves (Stirati and Cesaratto 1995). Nonetheless, the Italian-and the Chinese-PhDs are fully part of the internationalisation of the degree (Enders 2004), which no doubt has some effect in terms of homogenising quality (Nerad and Heggelund 2008).

As Morley et al. (2002, p. 264) noted, "Successful PhD completion is a key performance indicator for universities." It represents prestige, intellectual weight and the ability to compete in the education market. The last of these attributes is strongly reflected in the astonishing way that universities have thrown caution to the winds and embraced the neo-liberal model of education as a commodity to be manufactured, sold and bought. As Morley et al. (2003, p. 69) put it, "In the new market culture of consumer rights, with students constructed [sic] as paying customers, rather than recipients of a welfare service, the problems of doctoral assessment are likely to increase as investors in the educational product want more certainty and reliability of outcome." What this statement neglects to add is that a 
reliable outcome is not necessarily a high quality one. Frick et al. (2017) noted that this model tends to take away scholars' and scientists' independence, including their ability to criticise the sponsors of research.

The alternative to the neo-liberal university is usually regarded as the traditional one in which researchers are shielded from the worst effects of market forces. In the literature on the $\mathrm{PhD}$, there are both proponents and opponents of each model. For example, the neo-liberal view is upheld by Tinkler and Jackson (2000) and Vilkinas (2002), who see health and vitality in market forces. The most trenchant defence of neo-liberalism in universities came from Taylor (2011, p. 261), who argued that the traditional model is not only antiquated, but "education is a process of cloning that trains students to do what their mentors do" [our italics]. He proposed modernising the system by giving more decision-making power to administrators (i.e., taking it away from research supervisors and heads of doctoral schools). In our view,

110 this would be fatal: presumably Taylor's reformed doctorate would produce clones of the business managers instead of the supervisors. The anti-neo-liberal view has been defined by Morley et al. (2003) and defended by Kendall (2002). Evans and Kamler (2005) cast that process as a defence of scholarship.

\section{Supervision, students and standards}

115 There, in the middle of the cross-fire, are the students and their supervisors. A comment by Morley et al. (2002, p. 266) is heavy with implied meaning-and perhaps foreboding: "In the power-laden micro-politics of the academy, many diverse interests are thus invested in the viva. It is almost an academic equivalent of debutantes being presented at court." Both Heath (2002) and Acker and Haque (2015) examined the 
120 effect of stress on students as they prepare to go through with this exercise, or ritual as it is sometimes characterised (Carter 2008).

Supervision is clearly one of the keys to successful completion of the PhD. Indeed, in some circumstances it is probably the key. Some authors have conceptualised it as a process of mentoring (Vilkinas 2002, Lindén et al. 2013), while others have seen it in pedagogical terms (Heath 2002, Lee 2008, Lovat et al. 2008, Adkins 2009, Robertson 2017). Yet other authors have been occupied with the human dimension (Mullins and Kiley 2002, Ives and Rowley 2005, Lovat et al. 2008, Morrison et al. 2011), and, finally, researchers in pedagogy have taken an experimental view of supervision (Johnston 1997, Holbrook et al. 2008). Heath (2002, p. 51) summed up a consensus when he noted that "close supervision usually yields results". Some of the authors have focused on the role of supervision on the outcome, from which Mullins and Kiley (2002) and Carter (2008) drew the obvious inference that the examination of the thesis is a test of both the student and his or her supervisors.

As these and other authors have noted, the examination is an attempt to impose standards of judgement on the end product of three, four or however many years of PhD study. Whether these standards are formal or nominal, and whether they represent a consensus on quality and rigour, has been the subject of much debate.

It is clear that the end product of doctoral studies can be highly variable from one discipline to another. Despite this, some authors have proposed benchmarking (Shaw and Green 2002). Others have advocated using a written contract between supervisor and student. (Hockey 1996). Yet others have suggested that there should 
be performance evaluation, with particular emphasis on the time taken to complete 145 the work (Wright and Cochrane 2010). Standards have been proposed and debated, or simply wished for (Nightingale 1984, Morley et al. 2002, Denicolo 2003), but the alternative view has also been advanced, namely that such measures are not necessary because they are already inherent in the lengthy reports that most examiners write (Holbrook et al. 2008).

\section{The examiner}

The arbiter of the thesis, and the person who applies the standards, however notional they are, is of course the examiner. Procedures vary by country and institution such that there may be between one and five examiners. Golding et al. (2014, p. 567) took a reassuring view in asserting that most examiners are consistent in their criteria and judgement. Moreover, various authors have argued that examiners would rather pass than fail a thesis and will do what they can to achieve that goal, hopefully without sacrificing standards. In a provocative and entertaining article, Grabbe (2003, p. 133) took a less reassuring view of the role of the examiner. In discussing the pressure to pass a student, he observed that "Feeling sympathy for a failed student, however, is not the same as assuming a miscarriage of justice." Picture the examiner who does fail a student, a process which is "devastating for the candidate, but [also] seriously traumatic for the examiner, caught between desire to 'give the student the benefit of the doubt' and the need to uphold standards, and potentially vilified" (Grabbe 2003, p. 129). Grabbe further argued that appeals against failure are more likely to be 165 attributed to inadequate supervision than unfair examination. In our experience, that is often not the case, and we more commonly see a collective failure to confront the 
reality of why a thesis is an inadequate submission for the degree. This aspect is considered in more depth in a later section of this paper.

\section{The published papers option}

Finally, there is now a small literature that critically appraises the route to a doctorate through a collection of published papers (Wilson 2002, Badley 2009). While the majority of doctoral theses are still unitary monographs, it is increasingly common to find the alternative option, or even the requirement, to submit a collection of papers published in peer reviewed journals prefaced by a learned introduction which highlights what it is that links them together (Breimer and Mikhailidis 1993). This is now a prevalent model in Scandinavia and it is increasingly common elsewhere, for example in Australia (Jackson 2013). In the United Kingdom, it started out as a socalled 'staff doctorate', meaning an easy way of giving a long-serving member of staff the $\mathrm{PhD}$ qualification for his or her previous efforts at publication (Davies and Rolfe 2009).

The advantage of this route to a doctorate is that the candidate already has a collection of peer-reviewed publications to his or her name without the need to repeat scholarship by extracting and abstracting parts of the thesis to form publishable papers. Furthermore, Badley (2009, p. 331) sought to justify the published papers option by arguing that "Publishability is one major criterion by which doctoral level work may be judged." However, although Badley (2009) argued that traditional theses tend to lead to publication after the thesis has been examined, this is no longer true. Such are the pressures and such is the need for speed, that today's doctoral candidates are pretty much bound to be writing for publication as they compile their monograph theses. 
Despite its popularity, the published paper route is fraught with risk. To begin with, the papers must represent a coherent development of thought and must therefore be complementary to one another. This is not easy to achieve with papers that are by definition stand-alone works. We have examined theses in which the papers are all slightly different versions of the same work, or where the candidate is one of numerous authors and has not had a dominant role in the writing of the paper (or the research that underpins it), and that fail to progress in any discernible direction. Of course, the same may happen with monograph theses, but it is more difficult to ignore the question of continuity between one chapter and another. It is especially worrying to see papers that enjoy a moderate success as separate works but do little to contribute to the whole work. We do not believe that a doctorate should be awarded merely for publishing a certain number of papers, regardless of what they mean in collective terms. That would merely demonstrate lack of depth and continuity in argument. Moreover, in the interests of adhering to basic standards, we 205 do not condone the inclusion of 'grey' literature in the collection of peer-reviewed papers (by 'grey' literature we mean that which has not been formally published in peer-reviewed journals).

As Badley (2009, p. 333) observed, "Coherence, in the context of the PhD by published work, may be regarded as a candidate's attempt to provide a convincing critical narrative about the overall intellectual position unifying the submitted articles or papers." Failure to be rigorous can lead to a whole catalogue of issues about quality that concern the eligibility of candidates, the nature of supervision and the value or outcome of assessment. Sapientia est iudicium! $!^{i}$ 


\section{Conclusion on the literature}

Although research on the phenomenon of the research doctorate has been published now for more than 30 years, interest in the topic has been sporadic and the research output in refereed journals is remarkably thin. Authors have had their enthusiasms, for example for the published papers route, for benchmarking and for contracts or standards, but most of the suggested innovations have not generated groundswells of opinion in their favour. The neo-liberal model of the "university as knowledge market--or factory" has been promoted and criticised. Empirical studies have revealed opinions and tendencies, but there are many areas in which very little has been done.

We work in disaster risk reduction, an academic and practical field that has existed on one form or another since 1917. It is now immensely popular and has begun to produce doctoral theses in quantity from a wide variety and geographical spread of institutions. Our knowledge of the field tells us that when we study disasters, we need to look beyond the superficial activators of the events to discover the root causes, which are sometimes known as 'underlying risk drivers'. Only in this way will we achieve a sufficiently deep and accurate understanding of events. Disaster risk and recovery management are subjects in which lives depend on the application of effective approaches and policies. Therefore, rigorous scientific research must be continuously applied in order to form a basis of accurate decision making by governments and agencies. Much of this applied research will come from students undertaking PhD work, hence the concerns expressed in this paper.

The same reasoning could be applied to the doctorates themselves. The radical transformation of universities through the application of the neo-liberal model 
of unfettered market capitalism has had an enormous impact on degree courses at 240 all levels, as have the social and economic changes that have taken place in the wider world and have affected students, funding bodies, professional institutions, and the quality of the workplace. The Mediaeval model of the university as a cloistered habitat of thinking and debate has been influenced--or perhaps swept away--by ideologies based on market forces. Governments have had a hand in this 245 transformation, and not all protagonists of the PhD have appreciated their efforts. Evans and Kamler (2005, p. 118) argued that: "in the name of scholarship we have to fight back against the tendency of government agendas to subvert the purpose of doctoral education." This, of course, presupposes that we have a consensus on what that purpose is. In our view, rather than a consensus, it is increasingly a battleground (Kendall 2002), as the following paragraphs suggest.

\section{A model of problems}

The disappointed reader may wonder why our model should seek to characterise only problems, and not solutions. We will conclude with some reflections on that issue, but in order to know what the solutions are we first have to understand the problems, and their magnitude and extension. Let us be clear that we are not presenting the results of a statistical survey. In that sense, we are open to the criticism that our work sees only part of the phenomenon, perhaps what in our pessimism we want to see. However, we have encountered these issues over and 260 over again, and this has convinced us that there is a pattern to be discovered and brought out. Our observations are based on examining tens of theses in different universities, countries and continents. In each case we have written a report on the 
thesis, as judiciously as possible, and in many, but not all, cases the work has gone to oral examination, usually with positive results. Like Grabbe (2003) we remember 265 very clearly the stress and strain on both sides of the room when we have had to fail candidates.

The first of the problems we identify is ignorance. There seems to be an increasing tendency of academic staff members to take on theses in fields which they do not know well enough to supervise. We have known students arrive at the viva without learning the name of the principal authority in their chosen field, or studying his or her work. In some cases they have not made the effort to discover and visit a centre of expertise in their chosen field. All of these omissions are something that should have been corrected at a very early stage by the supervisor (Davis 2016). Although most students who face the ignorance of supervisors are victims, there are 275 a few who, through laziness, see the institution as a pushover, such that there is no need to make much effort to get to grips with the subject under study. A diligent external examiner might fervently disagree.

Our second problem is nepotism. Perhaps the student is on the staff, or is very close to the staff, or is married to a staff member or one of his or her supervisors. When it comes to the examination such a person may feel a considerable sense of personal invulnerability.

Thirdly, there are various forms of corruption. The ostensible reasons why an external examiner is appointed are to confer visible impartiality on the examination, make use of expertise from outside the university, and ensure that common standards are applied. However, the candidate's supervisors may assume that the external examiner is someone who can be relied upon to yield to pressure to pass 
the candidate regardless of the quality of the thesis. In any case, if the external expert refuses to pass the thesis, it may go to appeal and his or her judgement may be overruled, in some cases summarily, without open discussion, and with few or no controls on the process of re-examining the thesis. We have both seen this happen, although it would obviously be injudicious of us to discuss specific cases.

Money plays a considerable role in this process. Where a student has paid very high fees for three or four years there may be pressure to justify the expenditure by passing the thesis. Scholarships that involve a contract in which the funding is 295 dependent on completion of the degree may be particularly susceptible to this problem. A university may be extremely unwilling to upset a funding body by demonstrating that its investment in an incompetent student was misguided. Another issue with money is encountered with the naked or near naked institution that is short of $\mathrm{PhD}$ passes for its teaching or research assessment and therefore has to generate them by all means possible, including subverting the examination.

Fourthly, we have encountered negligence. In some cases, the student may refuse to take the advice of the supervisor. If this is patently unacceptable or illjudged, that is the right approach, but we have known cases of theses submitted against the supervisor's advice that have failed as a result. Alternatively, the supervisor may be competent but too busy or too lazy to supervise the student, whose work eventually goes to examination regardless of what is wrong with it.

From his extensive experience of $\mathrm{PhD}$ examining, Grabbe (2003) described a memorable case in which the thesis became a battleground between the student, the supervisor and the university, with the external examiner caught in the cross-fire. We have both had similar experiences. They were not resolved in any way that could be 
described as ethically acceptable. The greatest arguments for upholding standards are two. First, passing a sub-standard thesis is a disservice to the work of those students whose theses are good and excellent. It can devalue the PhD. Secondly, the doctorate seriously needs its standards if the scholars and scientists of the future are to benefit from insightful, inspired and rigorous training. So much ingenuity is required to solve society's problems that we cannot afford for the producers of those ideas to be mediocre thinkers.

\section{Setting the 'gold standard'}

We have stated that PhD research needs to set the 'gold standard' for all academic research endeavours. Therefore, in rounding off our paper, we believe that the 325 following steps need to be taken by the various actors and maintained over time. The university. Everything starts here. University leaders, senates and governing bodies need to devise an agreed policy to ensure the quality and excellence of PhD work. Criteria are needed to establish and constantly to monitor which departments and academic staff are qualified to supervise high quality $\mathrm{PhD}$ research.

The academic department. To preserve their reputations and integrity, academic departments need to define where their expertise lies with much care. To undertake the supervision of effective, ground-breaking $\mathrm{PhD}$ research they need to be highly capable in the field in question. The staff who supervise the PhD work should be authoritative in the field. Anything less will clearly lead in the direction of sub- 
335 standard research, potentially with damage to the reputation of the department and university, and to the subject in question.

The PhD supervisor. The responsibility lies with qualified academic staff to take on the supervision of research only in fields or sub-fields in which they have an established track record of competency, or, better still, excellence. We have heard it suggested that supervisors only need to be well-versed in research methods, rather than in the subject under study, and we totally reject this claim. With every new enrolment in a $\mathrm{PhD}$ programme, supervisors need to ask themselves whether they have the time and energy to take on the student and give him or her the dedicated attention required and for which the student will probably pay substantial fees.

The external examiner. The examiner carries a vital responsibility for providing 'quality assurance'. An external examiner needs:-

- to be robust and decisive against intimidation, however subtle its expression may be

- to be conscientious in reading every word of a dissertation, a process which may take several days of undivided attention

- to have complete command of the field of research, and this requires a high level of discernment, self-awareness and honesty in deciding whether the person is fit to accept the role of examiner or not.

The student. Before applying to a programme of study or department, the student 355 needs to play his or her part in verifying the quality of the academic unit and potential supervisors. He or she needs to explore the track record of possible supervisors, noting their levels of expertise and experience as well as whether they have previously supervised PhD work with success. The issue that each student should 
note is that supervision is required from a person who has, not only read the 360 literature, but also helped create the subject under study through his or her own research and writing. This 'verification process' is particularly challenging and important for students who come from outside the country in which they wish to undertake their doctorates.

\section{Conclusions}

In the neo-liberal university, education is a product that is marketed to students, but with remarkably little leeway for correction if it happens to be a faulty product. Most $\mathrm{PhD}$ degrees are not purchased, but there is an increasing risk that the monetarisation of higher education will encourage that to happen. The model relies on relentless growth and vigorous competition. Both of these traits produce instability. Neither is conducive to good results in academic work, which needs stability and cooperation. The most remarkable aspect of this situation is that universities, which should have defended Enlightenment values of truth, objectivity and humanity, so often embrace wholeheartedly the neo-liberal model which

375 threatens to cause their demise. Such is the academic world of administrators, the controllers of resources, who pay the piper and call the tune, and how limited in outlook it is!

Many of the problems of the modern doctorate stem from the underlying tendency to commodify education. It is remarkable how little has been written about that in the context of the PhD degree. We hope that our modest contribution will stimulate further debate and, with luck, insight. The answers to the problems we have 
outlined are actually quite simple: honesty, application, fair judgement and common sense, but coupled with appropriate, although even-handed, firmness.

Lastly, it is not our intention to suggest that all PhD theses are bad. We fully accept that very many of them are either good or excellent. We do not wish to see these works diminished by classifying them along with work of patently inferior quality. One criticism levelled against our previous work in this field (Alexander and Davis 2014) was that it tended to treat the examination as the cure for problems. We hasten to correct this impression. In negative cases, the examination is the last bulwark against problems that have usually arisen during the three of four years prior to it happening, but it does tend to throw light on these problems. Carter (2008, p. 370) was right when he observed that "it is easy to find oneself examining the supervisor."

\section{References}

Acker, S. and Haque E. (2015), "The Struggle to Make Sense of Doctoral Study", Higher Education Research and Development, Vol. 34 No.2, pp. 229-241.

Adkins, B. (2009), "PhD Pedagogy and the Changing Knowledge Landscapes of 400 Universities". Higher Education Research and Development, Vol. 28 No. 2, pp. 165-177.

Aitchison, C., Kamler B. and Lee A. (2010), Publishing Pedagogies for the Doctorate and Beyond, Routledge, London.

Alexander, D.E. and Davis I.R. (2014), "Fit to Supervise?" Times Higher Education, 405 20 February 2014, pp. 36-38. 
Andersen, J.P. and Hammarfelt B. (2011), "Price Revisited: on the Growth of Dissertations in Eight Research Fields", Scientometrics, Vol. 88 No. 2, pp. 371383.

Badley, G. (2009), "Publish and be Doctor-Rated: the PhD by Published Work," Quality Assurance in Education, Vol. 17 No. 4, pp. 331-342.

Breimer, L.H. and Mikhailidis D.P. (1993), "Towards a Doctoral Thesis Through Published Works," Biomedicine and Pharmacotherapy, Vol. 47 No. 9, pp. 403407.

Carter, S. (2008), "Examining the Doctoral Thesis: a Discussion," Innovations in Education and Teaching International, Vol. 45 No. 4, pp. 365-374.

Cyranoski, D., Gilbert, N. Ledford, H. Nayar A. and Yahia M. (2011), "The PhD Factory", Nature Vol. 472, pp. 276-279.

Davies, R.E. and Rolfe G. (2009), "PhD by Publication: a Prospective as Well as Retrospective Award? Some Subversive Thoughts", Nurse Education Today, Vol. 29, pp. 590-594.

Davis, I. (2016), "Reflections: Resolving Conflicting Demands Within Risk Reduction and Recovery," Environmental Hazards, Vol. 15 No. 3, pp. 269-278.

Denicolo, P. (2003), "Assessing the PhD: a Constructive View of Criteria," Quality Assurance in Education, Vol. 11 No. 2, pp. 84-91.

425 Enders, J. (2004), "Research Training and Careers in Transition: A European Perspective on the Many Faces of the Ph.D", Studies in Continuing Education, Vol. 26 No. 3, pp. 419-429. 
Evans, T. and Kamler B. (2005), "The Need for Counter-Scrutiny: Taking a Broad View of Doctoral Education Research," Higher Education Research and 430 Development, Vol. 24 No. 2, pp. 115-118.

Frick, L., McKenna S. and Muthama E. (2017), "Death of the PhD: When Industry Partners Determine Doctoral Outcomes," Higher Education Research and Development, PhD by Publication: a Prospective as Well as Retrospective Award? Some Subversive Thoughts Vol. 36 No. 2, pp. 444-447.

435 Golding, C., Sharmini S. and Lazarovitch A. (2014), "What Examiners Do: What Thesis Students Should Know", Assessment and Evaluation in Higher Education, Vol. 39 No. 5, pp. 563-576.

Grabbe, L.L. (2003), "The Trials of Being a PhD External Examiner", Quality Assurance in Education, Vol. 11 No. 2, pp. 128-133.

Heath, T. (2002), "A Quantitative Analysis of PhD Students' Views of Supervision", Higher Education Research and Development, Vol. 21 No. 1, pp. 41-53.

Hockey, J. (1996), "A Contractual Solution to Problems in the Supervision of PhD Degrees in the UK," Studies in Higher Education, Vol. 21 No. 3, pp. 359-371.

Holbrook, A., Bourke, S. Lovat T. and Fairbairn H. (2008), "Consistency and 445 Inconsistency in PhD Thesis Examination", Australian Journal of Education, Vol. 52 No. 1 , pp. 36-48.

Ives, G. and Rowley G. (2005), "Supervisor Selection or Allocation and Continuity of Supervision: Ph.D. Students' Progress and Outcomes," Studies in Higher Education, Vol. 30 No. 5, pp. 535-555. 
450 Jackson, D. (2013), "Completing a PhD by Publication: A Review of Australian Policy and Implications for Practice", Higher Education Research and Development, Vol. 32 No. 3, pp. 355-368.

Johnston, S. (1997), "Examining the Examiners: An Analysis of Examiners' Reports on Doctoral Theses", Studies in Higher Education, Vol. 22 No. 3, pp. 333-347.

Kendall, G. (2002), "The Crisis in Doctoral Education: A Sociological Diagnosis", Higher Education Research and Development, Vol. 21 No. 2, pp. 131-141.

Lee, A. (2008), "How are Doctoral Students Supervised? Concepts of Doctoral Research Supervision", Studies in Higher Education, Vol. 33 No. 3, pp. 267281.

460 Lee, A. and Danby S. (Eds) (2011), Reshaping Doctoral Education: International Approaches and Pedagogies, Routledge, Abingdon and New York.

Lindén, J., Ohlin M. and Brodin E.M. (2013), "Mentorship, Supervision and Learning Experience in PhD education", Studies in Higher Education, Vol. 38 No. 5, pp. 639-662.

465 Lovat, T., Holbrook A. and Bourke S. (2008), "Ways of Knowing in Doctoral Examination: How Well is the Doctoral Regime?" Educational Research Review, Vol. 3 No. 1, pp. 66-76.

Morley, L., Leonard D. and David M. (2002), "Variations in Vivas: Quality and Equality in British PhD Assessments", Studies in Higher Education, Vol. 27 No. 3, pp. 263-273.

Morley, L., Leonard D. and David M. (2003), "Quality and Equality in British PhD Assessment," Quality Assurance in Education, Vol. 11 No. 2, pp. 64-72. 
Morrison, E., Rudd E., Picciano J. and Nerad M. (2011), "Are you Satisfied? PhD Education and Faculty Taste for Prestige: Limits of the Prestige Value System", Research in Higher Education, Vol. 52 No. 1, pp. 24-46.

Mullins, G. and Kiley M. (2002), "'It's a PhD, Not a Nobel Prize': How Experienced Examiners Assess Research Theses", Studies in Higher Education, Vol. 27 No. 4, pp. 369-386.

Nerad, M. and Heggelund M. (Eds) (2008), Toward a Global PhD? Forces and Forms 480 in Doctoral Education Worldwide. Center for Innovation and Research in Graduate Education, University of Washington. University of Washington Press, Seattle.

Nightingale, P. (1984), "Examination of Research Theses", Higher Education Research and Development, Vol. 3 No. 2, pp. 137-150.

Park, C. (2005), "New Variant PhD: The Changing Nature of the Doctorate in the UK", Journal of Higher Education Policy and Management, Vol. 27 No. 2, pp. 189-207.

Robertson, M.J. (2017), "Team Modes and Power: Supervision of Doctoral Students", Higher Education Research and Development, Vol. 36 No. 2, pp. 358-371.

490 Shaw, M. and Green D.H. (2002), "Benchmarking the PhD: A Tentative Beginning", Quality Assurance in Education, Vol. 10 No. 2, pp. 116-124.

Stirati, A. and Cesaratto S. (1995), "The Italian Ph.D Ten Years On: Educational, Scientific and Occupational Outcomes", Higher Education, Vol. 30 No. 1, pp. $37-61$.

495

Taylor, M. (2011), "Reform the PhD System or Close It Down," Nature, Vol. 472, p. 261. 
Tinkler, P. and Jackson C. (2000), "Examining the Doctorate: Institutional Policy and the PhD Examination Process in Britain", Studies in Higher Education, Vol. 25 No. 2, pp. 167-180.

500 Tinkler, P. and Jackson C. (2004), The Doctoral Examination Process: A Handbook for Students, Examiners and Supervisors, Society for Research into Higher Education/Open University Press, Maidenhead, UK.

Vilkinas, T. (2002), "The PhD Process: The Supervisor as Manager", Education + Training, Vol. 44 No. 3, pp. 129-137.

505 Wilson, K. (2002), "Quality Assurance Issues for a PhD by Published Work: A Case Study", Quality Assurance in Education, Vol. 10 No. 2, pp. 71-78.

Wright, T. and Cochrane R. (2010), "Factors Influencing Successful Submission of PhD Theses", Studies in Higher Education, Vol. 25 No. 2, pp. 181-195.

\footnotetext{
'The wisdom of the judges.
} 